\title{
O Uso Próprio de Sementes Salvas e suas Relações com o Direito de Propriedade Intelectual dos Obtentores Vegetais Brasileiros
}

\author{
Saved Seeds and its Connections With the Intellectual Property Rights of \\ Brazilian Breeders
}

\author{
Fabio Lima Cordeiro ${ }^{1}$ \\ Luiz Antonio Soares Romeiro ${ }^{1}$ \\ ${ }^{1}$ Universidade de Brasília, Brasília, DF, Brasil
}

\begin{abstract}
Resumo
No Brasil, os direitos de propriedade intelectual vegetal são regulados pela Lei n. 9.456/97, conhecida como Lei de Proteção de Cultivares (LPC). Após mais de 20 anos em vigência, revisões dessa norma são necessárias, entre elas o dispositivo legal referente ao uso próprio de sementes salvas, que devido a interpretações equivocadas, tem provocado desvio de finalidade deste instituto, favorecendo a pirataria de sementes e consequentes violações de direitos de propriedade intelectual dos obtentores. A finalidade desta pesquisa é analisar os aspectos relacionados ao uso próprio de sementes salvas na legislação nacional e quais os desvios que ocorrem neste instituto e que violam os direitos dos obtentores. São apresentados os dados de cultivares protegidas, do mercado de sementes, bem como as informações sobre sementes salvas e a fiscalização realizada no país. Por fim, nas considerações finais, é feita uma proposta de alteração na legislação.
\end{abstract}

Palavras-chave: Proteção de Cultivares. Uso Próprio. Sementes Salvas. Propriedade Intelectual Vegetal.

\begin{abstract}
In Brazil, intellectual property rights of new plant varieties are regulated by the Cultivation Protection Act (LPC). After more than 20 years in enforcement, revisions in this law are necessary, especially the legal provision regarding the use of saved seeds, which, due to misinterpretations, have led to the diversion of the use of this institute, favoring seed piracy and consequent violation of the intellectual property rights of breeders. This paper analyzes the aspects related to the legal contents of saved seeds in Brazilian legislation and which deviations can occur in this institute that violate the rights of breeders. Results presents data on protected cultivars, seed market, saved seeds, inspection carried out in the country. Finally, in the final remarks, a proposal for amendment of the legislation.
\end{abstract}

Keywords: Protection of New Varieties of Plants. Saved Seeds. Intellectual Property Rights.

Área Tecnológica: Proteção de Cultivares. 


\section{Introdução}

Inicialmente, a propriedade intelectual dividia-se em direito autoral e propriedade industrial, mas com o desenvolvimento tecnológico de novas áreas surgiram outras necessidades de proteção, como a categoria sui generis, na qual está inserida a proteção de cultivares (FERREIRA, 2010b; BRASIL, 2011; GHESTI, 2016).

A literatura na temática da propriedade intelectual vegetal é relativamente pequena em comparação aos outros tipos de propriedade intelectual (SANTOS, 2018); enquanto se produz considerável quantidade de conhecimento nas áreas de patentes e direitos autorais, encontra-se pouca produção de textos sobre proteção de cultivares. Entretanto, esse tipo de propriedade intelectual é, provavelmente, o tipo mais abrangente e presente no cotidiano da população mundial, pois se relaciona diretamente com os alimentos que estão à mesa diariamente, já que grande parte do que é consumido na alimentação humana tem nos vegetais a sua matéria-prima básica.

Desde a criação da União Internacional para Proteção das Obtenções Vegetais (UPOV) em 1961, a comunidade internacional reconhece a importância e a necessidade de se construir sistemas efetivos de proteção de novas variedades de plantas, obtidas por meio de melhoramento genético, em prol da sociedade (AVIANI; MACHADO, 2011). O instrumento legal que regulamenta essa proteção no Brasil é a Lei n. 9.456, de 25 de abril de 1997 (BRASIL, 1997), popularmente conhecida como Lei de Proteção de Cultivares (LPC).

A referida lei, na época de sua promulgação, inovou a legislação brasileira ao prever direitos de propriedade intelectual para os obtentores que melhorassem a qualidade genética de plantas. Em seu texto, a LPC traz os mesmos preceitos da Ata da UPOV de 1978, com alguns outros da Ata de 1991, embora o Brasil seja signatário apenas da Ata da UPOV de 1978 (FERREIRA, 2010a).

A proteção garantida pela LPC se refere ao melhoramento genético vegetal tradicional, feito de forma natural, sem aplicação de modificações genéticas artificiais. Para plantas transgênicas, ou seja, as modificadas geneticamente, é aplicada a Lei de Propriedade Industrial (LPI), Lei n. 9.279, de 14 de maio de 1996 (BRASIL, 1996), sendo que, nos termos da Lei de Biossegurança, Lei n. 11.105, de 24 de março de 2005 (BRASIL, 2005), o órgão responsável por autorizar, cadastrar e acompanhar as atividades de pesquisa com organismo geneticamente modificado (OGM) ou dele derivado, bem como a tramitação dos pedidos de liberação para comercialização, é a Comissão Técnica Nacional de Biossegurança (CTNBio). Atualmente, na área de vegetais modificados geneticamente, estão aprovados a transgenia no Brasil, pela CTNBio, algumas cultivares específicas de soja, milho e algodão, principalmente, e também feijão, eucalipto $e$ cana-de-açúcar (BRASIL, 2019b), sendo que cada pedido é analisado individualmente, ou seja, a liberação para comercialização vem após o estudo caso a caso.

Após mais de 20 anos da LPC, diversos agentes dos setores agrícolas do país, como a Associação Brasileira de Sementes e Mudas (ABRASEM) e a Associação Brasileira dos Produtores de Sementes de Soja (ABRASS), reconhecem a necessidade de atualização da lei. A LPC, em seu artigo 10 (BRASIL, 1997), permite que o agricultor guarde sementes para usar na safra seguinte, sem ferir o direito de propriedade intelectual do obtentor. Essas sementes guardadas são as sementes salvas. A lei restringe ainda em seu artigo 10 que essas sementes sejam usadas apenas para uso próprio, na propriedade de posse do agricultor, ou seja, não podem ser comercializadas. 
Diante desse dispositivo legal, entidades atuantes no mercado brasileiro de sementes, como a Associação Brasileira de Sementes e Mudas (ABRASEM) e a Associação Brasileira dos Produtores de Sementes de Soja (ABRASS), alegam que o uso próprio de sementes salvas é responsável por uma pirataria que, no caso das sementes de soja, chega a atingir $30 \%$ da produção nacional, violando os direitos de propriedade intelectual dos obtentores vegetais nacionais (ABRASS, 2016).

A finalidade desta pesquisa é analisar os aspectos relacionados ao uso próprio de sementes salvas na legislação nacional de proteção de cultivares, especificamente o inciso I do artigo $10^{\circ}$ da LPC, e quais os desvios que ocorrem neste instituto que violam os direitos dos obtentores brasileiros.

\section{Metodologia}

Trata-se de pesquisa exploratória, para uma maior familiaridade com o tema pesquisado, visto que ainda é pouco conhecido e explorado, de método indutivo e comparativo, natureza qualitativa e coleta de dados analítica. Diniz e Silva (2008) colocam que no método indutivo os argumentos para o pensar partem de observações particulares (premissas), tomadas a priori como verdadeiras, para as generalizações conceituais (conclusões) que podem ser verdadeiras ou não. Nesta pesquisa parte-se da premissa de que o problema do comércio ilegal de sementes que ocorre no Brasil é consequência da permissividade da LPC no uso de sementes salvas.

Sua natureza é qualitativa, uma vez que, conforme definiram Silveira e Córdova (2009), não tem preocupações apenas com a representação numérica, mas, sobretudo, com a compreensão do objeto por meio de dados não métricos.

As técnicas de coleta de dados utilizadas foram: pesquisas bibliográficas e documentais realizadas em bases de dados nacionais e internacionais. Os procedimentos adotados adequam-se à pesquisa de natureza qualitativa, conforme descrito por Gil (2002). A pesquisa bibliográfica sobre o tema foi realizada na Base de Dados da Pesquisa Agropecuária (BDPA), no Portal Scielo e no Portal de Periódicos CAPES.

\section{Resultados e Discussão}

Decorridos mais de 20 anos de promulgação da Lei de Proteção de Cultivares do Brasil, diversos autores utilizados como fontes desta pesquisa (PEIXOTO; VILELA, 2018; LEITÃO, 2017; SANTOS, 2017; NUNES, 2016; BARBOSA, 2013; UTINO, 2012; AVIANI, 2011; LIMA; MACHADO, 2011; ANTUNES et al., 2008; CARVALHO; SALLES-FILHO; PAULINO, 2007; SILVA, 2005) entendem que sua implantação trouxe nova mentalidade aos produtores rurais sobre o tema da propriedade intelectual vegetal nas atividades de campo. Mais de 100 espécies, ao longo de 20 anos, já foram incluídas no regime de proteção. O Quadro 1 mostra as espécies protegidas no Serviço Nacional de Proteção de Cultivares (SNPC) segundo os seus respectivos grupos de cultivos. 
Quadro 1 - Grupos de cultivo registrados no SNPC segundo as espécies

\begin{tabular}{|c|c|}
\hline EsPÉCIE & Grupos de Cultivo \\
\hline Olerícolas & $\begin{array}{l}\text { Quiabo, cebola, pimentão/pimenta, melancia, melão, abóbora, cenoura, } \\
\text { morango, alface, feijão-vagem, ervilha, tomate, estevia. }\end{array}$ \\
\hline Florestais & Eucalipto, seringueira. \\
\hline Forrageiras & $\begin{array}{l}\text { Amendoim forrageiro, braquiária (cinco espécies), bromus, guandu, capim-dos- } \\
\text { pomares, capim-pé-de-galinha, festuca, capim-lanudo, azevém, lótus, macrotyloma, } \\
\text { capim-colonião, Paspalum vaginatum, milheto, poa, trevo-vermelho. }\end{array}$ \\
\hline Frutíferas & $\begin{array}{l}\text { Goiaba serrana, kiwi, abacaxi, laranja, maçã, manga, banana, oliveira, } \\
\text { maracujá, guaraná, abacate, pêssego/nectarina, pera, mirtilo, videira. }\end{array}$ \\
\hline Grandes Culturas & $\begin{array}{l}\text { Amendoim, aveia, café, algodão, girassol, cevada, tabaco, arroz, feijão, cana- } \\
\text { de-açúcar, centeio, batata, sorgo, trigo, feijão caupi, triticale, milho. }\end{array}$ \\
\hline Ornamentais & $\begin{array}{l}\text { Alstroeméria, antúrio, aster, begônia, crisântemo, cróton, cúrcuma, cimbídio, grama- } \\
\text { bermuda, cravo, poinsétia, fícus, gérbera, guzmânia, gypsophila, hibisco, amarílis, } \\
\text { hortênsia, hipérico, impatiens, calancoe, lírio, estatice, roseira, violeta africana, } \\
\text { solidago, lírio-da-paz, grama-santo-agostinho, copo-de-leite, grama-esmeralda. }\end{array}$ \\
\hline
\end{tabular}

Fonte: Brasil (2011)

Dados de pedidos de proteção, bem como os dados de proteções concedidas, obtidos junto ao SNPC desde a aprovação da Lei (MACHADO, 2017) constatam um crescimento exponencial pelo interesse dos obtentores em proteger suas novas variedades, o que pode ser observado no Gráfico 1. Nos primeiros 20 anos de existência da proteção de cultivares no Brasil, ou seja, até 2017, o SNPC recebeu mais de quatro mil pedidos de proteção de novas cultivares e concedeu nesse mesmo período mais de três mil certificados de proteção.

Gráfico 1 - Pedidos de proteção de novas cultivares versus concessões por ano

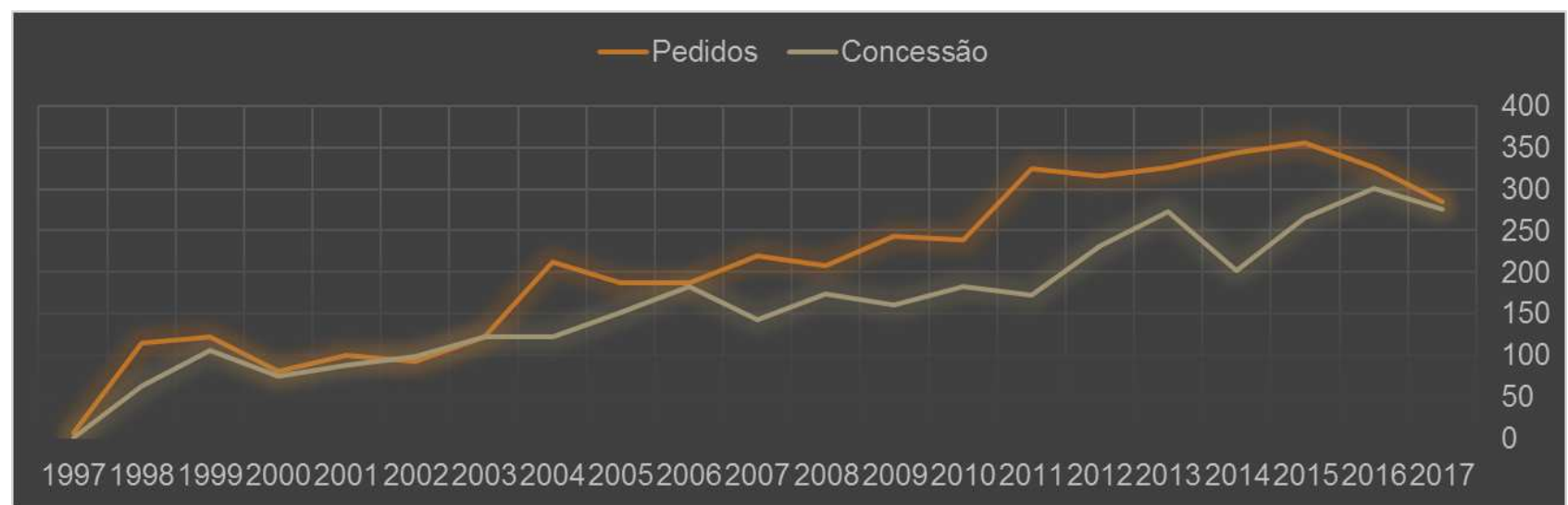

Fonte: Machado (2017)

Em relação aos pedidos de proteção por culturas, percebe-se no Gráfico 2 que o maior interesse em proteção se dá para as grandes culturas (65\% do total), em especial soja, milho, trigo, arroz e algodão, de onde se extrai as informações de distribuição de certificados de proteção de cultivares concedidos pelo SNPC, segundo a espécie, até o ano de 2017. Fato que reforça esse interesse é que as grandes culturas, especialmente a soja, são commodities com alta participação e lucratividade no agronegócio brasileiro (CARVALHO; SALLES-FILHO; PAULINO, 2007). 
Gráfico 2 - Distribuição de certificados de proteção de cultivares no SNPC, segundo a espécie, até 2017

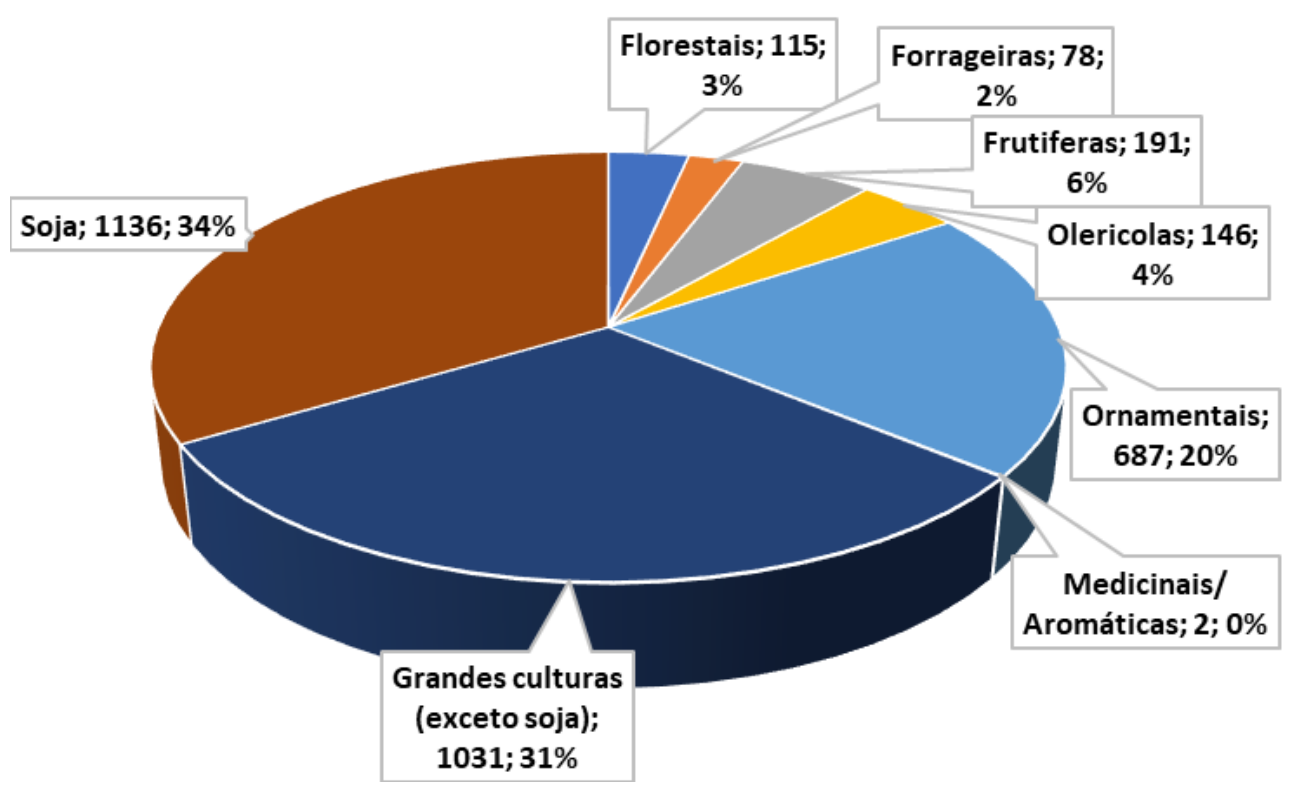

Fonte: Machado (2017)

Para que essas novas cultivares se tornem insumos agrícolas para o agronegócio é essencial que suas sementes estejam disponíveis aos agricultores e produtores rurais, de forma a demonstrar seu comportamento superior no campo (NUNES, 2016). O potencial genético de uma cultivar é expresso, na lavoura, por meio do ótimo desenvolvimento das sementes. As exigências produtivas da agricultura moderna requerem a multiplicação e disseminação rápida e eficaz das cultivares modernas, aliadas à manutenção das características superiores delas. A multiplicação dessas sementes se dá através de pequenas quantidades que geram volumes em escala comercial. A semente é o veículo que leva ao agricultor todo o potencial genético de uma cultivar com características superiores (NUNES, 2016).

\subsection{Mercado de Sementes}

Atualmente, o Brasil ocupa as primeiras posições entre principais produtores agrícolas mundiais. No entanto, a produção de sementes é, basicamente, destinada para grandes culturas, como soja, milho, trigo, arroz e algodão. Além dessas culturas, o Brasil também é líder na produção e exportação de sementes de forrageiras tropicais. No entanto, o país importa sementes destinadas à produção de hortaliças e flores (EMBRAPA, 2017). O mercado de sementes movimenta $R \$ 10$ bilhões ao ano no Brasil, que tem a terceira maior indústria do mundo no setor, atrás de Estados Unidos e da China (GALIOTTO, 2017).

O mercado de sementes conta com a presença do setor público, de grandes empresas multinacionais e de pequenas empresas nacionais, sendo que a participação no mercado é determinada por variáveis como a) tipo de cultivo; b) comercialização; c) capacidade competitiva; d) produção; e) distribuição e; f) assistência técnica (CORDEIRO; PEREZ; GUAZZELLI, 2007). No setor público, a Empresa Brasileira de Pesquisa Agropecuária (Embrapa) é a grande 
líder, enquanto no setor privado há mais de uma líder, destacando-se grandes empresas do agronegócio, como Bayer e Syngenta. Há empresas que dominam toda a cadeia, com grande capacidade de investimento na área de melhoramento vegetal. Há outras empresas que operam apenas como multiplicadoras de material genético desenvolvido pela Embrapa ou por grandes empresas privadas (CORDEIRO; PEREZ; GUAZZELLI, 2007).

Tomando a soja como exemplo, o Sistema Cultivar Web do SNPC (2019) aponta que a maioria dos obtentores e produtores brasileiros está no setor privado, com $79 \%$ da titularidade das cultivares de soja registradas; o setor público vem em seguida com $20 \%$; e $1 \%$ é de parcerias público-privadas, onde o direito de propriedade intelectual está compartilhado entre um ente público e uma empresa privada. As principais instituições detentoras dessas tecnologias de soja são a Embrapa (18\%), D\&PL (13\%), Bayer (12\%), Don Mario (10\%), Nidera Seeds Holding (9\%), Agrigenetics (8\%), GDM Genética do Brasil (4\%), Syngenta (4\%), TMG Tropical Melhoramento e Genética (4\%) e FTS Sementes (3\%). As outras empresas somadas possuem $15 \%$ das cultivares de soja registradas, em dados coletados até julho de 2019.

Desde a criação da Embrapa em 1973, o setor público construiu uma rede nacional de avaliação de cultivares, articulando programas de melhoramento mantidos por universidades e órgãos estaduais de pesquisa pública (CORDEIRO; PEREZ; GUAZZELLI, 2007). Dessa forma, foi possível garantir o desenvolvimento de programas de melhoramento vegetal que, depois da aprovação da LPC e demais marcos regulatórios, foram reforçados pelo setor privado. Por décadas, o setor público foi o pilar da indústria de sementes do País. Há uma maior predileção pelo setor privado no desenvolvimento de cultivares voltadas para o agronegócio, enquanto as empresas do setor público, além das commodities, investem no melhoramento genéticos de culturas com maior apelo social (NUNES, 2016).

Quando a LPC completou dez anos, autores como Cordeiro, Perez e Guazzelli (2007) assistiram a um processo crescente de concentração do mercado de sementes pelo setor privado seguindo a mesma tendência observada em outros países em desenvolvimento. Em 2019, após mais de vinte anos de aprovação da LPC, ao analisar os Anuários da Associação Brasileira de Sementes e Mudas (ABRASEM), constata-se que o mercado de sementes continua em franco desenvolvimento, crescendo mais de $80 \%$ nos últimos 6 anos, passando sua produção de sementes comercializadas de 2,45 milhões de toneladas na safra de 2011/12 (ABRASEM, 2014) para 4,59 milhões de toneladas na safra de 2017/18 (ABRASEM, 2019).

Além dessas culturas, os mercados de sementes forrageiras e olerícolas também tiveram crescimento expressivos nos últimos anos (ABRASEM, 2014). Em seu último anuário, a Abrasem (2019) apresentou a estatística de produção de sementes no Brasil, com dados coletados dos sistemas oficiais da Companhia Nacional de Abastecimento (CONAB) e do MAPA, o Sistema de Gestão da Fiscalização (SIGEF), confirmando que a Soja desponta com $66 \%$ do mercado de sementes, seguida do Milho (12,25\%), Forrageiras (7,05\%) e demais espécies.

Apesar dos dados demonstrarem que há crescimento positivo do setor de sementes, é preciso considerar que este desenvolvimento poderia ser maior caso não houvesse as ocorrências do comércio ilegal de sementes. O potencial de melhoria do setor, mesmo com essa adversidade, demonstra que investir em ações que mitiguem o uso de sementes não certificadas aumenta as condições para que os números do mercado de produção sejam mais expressivos que os atuais. 


\subsection{Sementes Salvas}

Segundo Silva (2005), semente salva é aquela produzida e guardada pelo agricultor ao final de sua colheita e que se prestará para seu exclusivo plantio na safra futura. Ou seja, o produtor que adquire sementes de determinada cultivar protegida, à medida que as planta, pode guardar sementes que resultam naturalmente do processo produtivo para serem usadas na próxima safra, sem pagar nada a mais, as chamadas sementes salvas (FARIAS, 2015a). Os royalties devidos ao obtentor que desenvolver a cultivar protegida são pagos na aquisição das sementes certificadas. Ao usar a semente salva, o produtor volta a usufruir da tecnologia adquirida, mas deixa de pagar novos royalties ao obtentor.

Essa prática é permitida no artigo $10^{\circ}$ da LPC, que diz: "Não fere o direito de propriedade sobre a cultivar protegida aquele que: I - reserva e planta sementes para uso próprio, em seu estabelecimento ou em estabelecimento de terceiros cuja posse detenha." (BRASIL, 1997, art. $10)$.

O legislador ao elaborar esse item resguardou aos pequenos produtores o direito de utilizar as sementes salvas a cada safra, inserindo no texto normativo a expressão "uso próprio".

O uso próprio no Brasil é uma prática cultural muito comum entre os agricultores, especialmente em Estados tradicionalmente agrícolas, como nas comunidades rurais do Rio Grande do Sul. Nesses locais, guardar a semente é uma tradição que vem de gerações. Além disso, em determinadas situações, salvar sementes pode garantir a continuidade da atividade agrícola, pois em decorrência das mudanças climáticas por vezes pode ocorrer desequilíbrio no fornecimento de sementes certificadas nos mercados. O uso próprio proporciona segurança para plantar na safra seguinte aquela semente que o produtor costuma usar (FARIAS, 2015a).

Considerando-se os dispositivos legais atuais, o produtor que tenha salvado suas sementes para plantar na próxima safra não infringe a lei, desde que as declare no Sistema de Gestão da Fiscalização (SIGEF) do MAPA. Para realizar a declaração, o produtor precisa informar o montante de sementes salvas, que deve ser compatível com a sua área de cultivo. Esse controle visa a impedir a comercialização indevida de sementes salvas (FARIAS, 2015b).

Segundo Silva (2005), essa concessão é considerada uma das exceções mais danosas ao direito de proteção do obtentor sobre uma cultivar, pois independente do seu tamanho, se pequeno agricultor ou grande produtor. A prática só pode ocorrer para uso próprio, sendo que qualquer comercialização sobre a quantidade extra ocasiona o comércio ilegal de sementes, ora denominadas sementes piratas.

Essa situação ocorre principalmente com culturas protegidas que são consideradas commodities agrícolas, como a soja, o trigo, o arroz e o milho (CARVALHO; SALLES-FILHO; PAULINO, 2007). Essa exceção provoca debilidade no direito de proteção dos obtentores, razão pela qual costuma ser o tema central em todos os Projetos de Lei em tramitação no Congresso Nacional para alteração da LPC. Além disso, como lembrado por Rodrigues, Campante e Barreto (2017), na LPC, as sanções previstas para aqueles que infringem os direitos dos obtentores estão colocadas em artigo único que versa sobre punições nas esferas administrativa, civil e penal, trazendo limitações de aplicabilidade ao dispositivo. O texto da lei diz: 
Aquele que vender, oferecer à venda, reproduzir, importar, exportar, bem como embalar ou armazenar para esses fins, ou ceder a qualquer título, material de propagação de cultivar protegida, com denominação correta ou com outra, sem autorização do titular, fica obrigado a indenizá-lo, em valores a serem determinados em regulamento, além de ter o material apreendido, assim como pagará multa equivalente a vinte por cento do valor comercial do material apreendido, incorrendo, ainda, em crime de violação dos direitos do melhorista, sem prejuízo das demais sanções penais cabíveis.

$\S 1^{\circ}$ Havendo reincidência quanto ao mesmo ou outro material, será duplicado o percentual da multa em relação à aplicada na última punição, sem prejuízo das demais sanções cabíveis.

$\S 2^{\circ} \mathrm{O}$ órgão competente destinará gratuitamente o material apreendido - se de adequada qualidade - para distribuição, como semente para plantio, a agricultores assentados em programas de Reforma Agrária ou em áreas onde se desenvolvam programas públicos de apoio à agricultura familiar, vedada sua comercialização.

$\S 3^{\circ} \mathrm{O}$ disposto no caput $e$ no $\S 1^{\circ}$ deste artigo não se aplica aos casos previstos no art. 10. (BRASIL, 1997, art. 37)

O parágrafo terceiro do artigo 37 confirma a limitação de aplicabilidade de penalidade para os casos de uso de sementes salvas.

Segundo dados da Associação Brasileira dos Produtores de Sementes de Soja (ABRASS), dos 33 milhões de hectares de soja cultivados no Brasil, $30 \%$ são plantados com sementes salvas, ou sem procedência de origem (ABRASS, 2016). Quando as sementes salvas não são utilizadas para uso próprio criam na prática um comércio ilegal de sementes (FARIAS, 2015b).

Farias (2015a) considera que essa prática ocorre devido ao alto valor atribuído à semente certificada no custo final da produção. Em relação a grãos por exemplo, a semente certificada com o pagamento de royalties representa em torno de $15 \%$ do custo total de produção. A Associação de Produtores e Comerciantes de Sementes e Mudas do Rio Grande do Sul (APASSUL) realizou um levantamento no estado do Rio Grande do Sul onde detectou que de um total de 5,9 milhões de hectares cultivados no ano de 2016 , em apenas $55 \%$ foram utilizadas sementes certificadas (APASSUL, 2017).

Dependendo da cultura, as sementes salvas ocasionam perdas do potencial genético da cultivar protegida (NUNES, 2016), e a comercialização desse germoplasma não qualificado levaria à deterioração moral do setor (FREITAS, 2017).

A Embrapa (2017) utiliza o termo pirataria em razão da violação dos direitos de propriedade intelectual do obtentor, uma vez que está ligada diretamente ao desrespeito dos acordos firmados em contratos, além de ferir as convenções internacionais onde ocorre cópia, venda ou distribuição de germoplasma sem o pagamento dos direitos autorais ou de marca. A Embrapa (2017) concorda com entidades do setor (ABRASEM, 2017; ABRASS, 2016) de que há um grande volume de sementes piratas sendo vendidas. Ao crer que estão levando vantagem pela compra de sementes mais baratas, os agricultores consumidores das sementes piratas levam para suas lavouras, na verdade, grãos que não são sementes. Para entender melhor essa questão, a Embrapa (2017) ainda afirma que: 
A semente é idêntica ao grão comercial, no entanto, em seu processo de produção, a semente tem finalidade de plantio e é produzida com cuidados especiais e obedecendo a normas técnicas, procedimentos e padrões estabelecidos pela legislação. A qualidade da semente envolve muitos aspectos, que nesse caso, deve se destacar pela qualidade genética, qualidade física, qualidade fisiológica e qualidade sanitária das sementes. (EMBRAPA, 2017)

Nunes (2016) coloca também que utilizar sementes piratas significa não ter garantia de qualidade, nem assistência técnica, e envolve também riscos fitossanitários, com a possibilidade de disseminação de doenças e pragas que podem causar grandes problemas. A semente certificada de uma cultivar protegida possui características de pureza varietal e de vigor que as sementes no mercado ilegal não possuem.

Alguns dos principais atores do mercado de sementes brasileiro consideram que a pirataria de sementes é reflexo da falta de fiscalização em relação ao uso de sementes salvas (RODRIGUES; CAMPANTE; BARRETO, 2017; ABRASS, 2016; CARVALHO; SALLES-FILHO; PAULINO, 2007; SILVA, 2005).

\subsection{Fiscalização das Sementes}

A fiscalização do mercado de sementes é realizada em território nacional pelas Superintendências Federais de Agricultura (SFA) do MAPA, por meios dos seus fiscais agropecuários federais, que são servidores de carreira do Ministério. As equipes que atuam em fiscalização de sementes verificam a documentação e qualidade da semente, conferindo se esta mantém o padrão autorizado para comercialização, bem como a manutenção das características declaradas na ocasião da proteção ou do registro de uma cultivar (NUNES, 2016).

A qualidade de um lote de sementes possui determinados padrões: qualidade física, fisiológica, de ausência de misturas varietais e de outras espécies de plantas cultivadas, de sementes de invasoras proibidas, além de não apresentar sementes deterioradas ou danificadas e que apresentem alto poder germinativo (NUNES, 2016).

Segundo Nunes (2016), "[...] ações específicas nesse sentido, denominadas pós-controle, são executadas por amostragem ou ainda quando há suspeita de que a cultivar não atenda mais aos requisitos para manter-se protegida". Os fiscais acompanham ainda a implantação $e$ a avaliação dos testes de DHE nas localidades onde foram requeridas proteção de cultivares.

Para exercer seu direito de salvar sementes, o agricultor deve preencher a "Declaração de Inscrição de Área para Produção de Sementes para Uso Próprio" por meio do SIGEF. A área utilizada para o plantio de sementes salvas deve ser compatível com a quantidade de sementes produzidas na safra anterior, considerando-se a área da propriedade do usuário. Sem essas informações declaradas, ou excedendo a quantidade permitida, a prática se torna ilegal e passível de penalidades como advertência, multa e apreensão das sementes. De acordo com o parágrafo único do artigo 43 da Lei de Sementes e Mudas, Lei n. 10.711,

[...] a multa pecuniária será de valor equivalente a até $250 \%$ (duzentos e cinquenta por cento) do valor comercial do produto fiscalizado, quando incidir sobre a produção, beneficiamento ou comercialização. (BRASIL, 2003, art. 43) 
Desde 2016 o SIGEF está disponível on-line para preenchimento da documentação requerida, sendo uma importante iniciativa do MAPA para combater o comércio ilegal de sementes. Esse sistema preencheu uma lacuna da fiscalização apontada por Cordeiro, Perez e Guazzelli (2007) na década anterior, quando não havia banco de dados com esses registros organizados. Hoje as informações quantitativas das declarações estão disponíveis no Painel Brasileiro de Sementes, mantido pelo MAPA. Entretanto, a plataforma apresenta apenas os dados do uso próprio de sementes salvas dentro da legalidade. Os dados relativos aos autos de infração emitidos pelos fiscais agropecuários são apresentados no site de fiscalização do MAPA.

Apesar dos recursos tecnológicos, ainda é preciso que a fiscalização seja realizada in loco. As ações de fiscalização dos fiscais agropecuários decorrem principalmente de denúncias realizadas pelos canais oficiais da Ouvidoria do MAPA, seja por telefone, e-mail e formulário eletrônico no site da ouvidoria. Em âmbito regional o MAPA conta com parcerias feitas com os fiscais agropecuários estaduais, realizando forças-tarefa interestaduais. Em Mato Grosso, a fiscalização da utilização de sementes "piratas" pelo agricultor foi delegada ao Instituto de Defesa Agropecuária de Mato Grosso (INDEA-MT) por meio de acordo de cooperação técnica (BRASIL, 2019a).

Outro importante ponto de apoio à fiscalização do MAPA são as campanhas educativas de entidades do setor sementeiro para conscientizar os agricultores, para que estes entendam os riscos do comércio ilegal de sementes e tomem a medida correta, de denunciar às autoridades competentes essas irregularidades. A campanha da ABRASS, lançada em 2016, chama-se "Combate à Pirataria" e a da ABRASEM, lançada em 2019, chama-se "Semente Pirata Espanta a Produtividade". Ambas as entidades oferecem seus canais de comunicação para a realização de denúncias.

\section{Considerações Finais}

A promulgação da Lei de Proteção de Cultivares no Brasil em 1997 foi um importante marco legal para a propriedade intelectual vegetal no país, além de ter relevante influência nas políticas públicas voltadas para a agricultura nacional.

Os ganhos com a LPC, além dos aspectos de segurança alimentar, foram também econômicos, pois possibilitaram ao governo atingir metas de aumento de produção agrícola, melhorar a segurança ao empreendedor, aos investimentos e à inovação, atrair investimentos nacionais privados na pesquisa de melhoramento vegetal, bem como atrair conhecimento e tecnologias estrangeiras para o país e agregar valor aos produtos vegetais brasileiros.

O Brasil tem produzido maior quantidade de produtos agrícolas ao longo dos anos, especialmente grãos, sem aumentar, na mesma proporção, a área plantada. Isso se deve basicamente às novas tecnologias desenvolvidas pela pesquisa agrícola que são expressas, principalmente, por novas variedades de plantas - maior resistência a pragas e doenças e maior produtividade, por exemplo.

No que tange à LPC, a necessidade de atualização da legislação nacional que rege os direitos dos obtentores brasileiros é latente, especialmente no quesito relacionado às sementes salvas. Nos aspectos referentes à propriedade intelectual considera-se a possibilidade de retorno financeiro pelos investimentos de novas invenções, seja para recuperar o investimento, seja para lucrar com o novo produto ou desenvolver novas tecnologias. No caso de novas variedades 
de plantas, o meio pelo qual o obtentor recupera o seu investimento, ou onde são cobrados os royalties de seu investimento em pesquisa, é no material propagativo da nova variedade, e não sobre a produção da nova variedade. As sementes são o principal meio de propagação das cultivares protegidas e sua indústria acaba por se tornar a base do agronegócio, principal porta de entrada do mercado agrícola.

Do ponto de vista da propriedade intelectual, os obtentores brasileiros precisam que a legislação vigente ofereça garantia do retorno dos investimentos realizados na produção de novas tecnologias, caso contrário, a premissa básica da propriedade intelectual - de que o investimento em inovação promove o desenvolvimento - será sobreposta. A atual legislação, em seu art. 10, inciso I diz que não fere o direito de propriedade sobre a cultivar protegida aquele que reserva e planta sementes para uso próprio, em seu estabelecimento ou em estabelecimento de terceiros cuja posse detenha (BRASIL, 1997). O princípio estabelecido pela Ata da UPOV de 1978 era de que o uso próprio fosse um direito dedicado em especial ao pequeno agricultor, para garantir a sua segurança alimentar e a sua manutenção no campo, o que foi seguido pelo legislador. Entretanto, a interpretação desse inciso tem sido aplicada de forma indiscriminada por qualquer agricultor, acarretando um desvio da finalidade desse instituto, considerado uma ameaça à segurança jurídica do regime jurídico atual que assegura os direitos de propriedade intelectual dos obtentores.

O uso próprio de sementes é uma prática amparada pela lei, desde que se limite a reservar as sementes salvas para que sejam plantadas na safra imediatamente seguinte e exclusivamente para consumo próprio. O que tem ocorrido na prática, de acordo com os levantamentos realizados neste trabalho, é que as sementes salvas têm gerado um comércio ilegal de sementes, ou seja, o dispositivo tem incentivado a circulação de sementes não certificadas, popularmente chamadas de piratas. Esse fato provoca um desestímulo muito grande para as empresas obtentoras e a cadeia como um todo.

No caso de sementes salvas, o prejuízo vai além dos royalties não recebidos pelo obtentor em razão do comércio ilegal. Há uma série de consequências negativas desse mercado ilegal que atingem de uma maneira geral os participantes da cadeia produtiva sementeira. Em uma análise de quem perde com essa situação aparecem inicialmente os obtentores, que não obtêm o retorno de investimentos em pesquisa e inovação; em seguida, os produtores de sementes, ou sementeiros, que enfrentam uma concorrência desleal com o preço das sementes certificadas versus o preço das sementes piratas; o agricultor/produtor, que adquire sementes sem garantia de qualidade, que resultam em baixa produção e produtividade na lavoura; o governo, com o afastamento dos investimentos em pesquisa e desenvolvimento no país e o não pagamento de impostos; e setor de sementes, com o desestímulo à geração de novos materiais com tecnologia no mercado.

Sementes não certificadas comercializadas de forma abusiva provocam ainda a redução dos investimentos na força de trabalho dos obtentores, e ainda colocam em risco a qualidade da produção, uma vez que a cada multiplicação ou geração o melhoramento da cultivar protegida perde o seu potencial inicial. Isso ocorre porque ao se multiplicar sementes de uso próprio, isso é feito sem as devidas técnicas e cuidados especiais utilizados pelos melhoristas, ocasionando perdas das características genéticas superiores por contaminação de cultivares convencionais não protegidas. 
Para proteger a propriedade intelectual dos obtentores, constata-se neste trabalho que o dispositivo da LPC que rege as sementes salvas deve ter conteúdo objetivo e transparente, permitindo a inequívoca interpretação e aplicação dos dispositivos legais e, portanto, deve ter sua redação alterada.

Alterar minimamente a redação de um dispositivo legal muitas vezes levanta em leigos o questionamento: quais mudanças ocorrerão na prática se o conceito de origem da norma permaneceu o mesmo? Aplicando no caso em questão, a pergunta seria: se já é proibido que sementes salvas sejam usadas com fim diverso do uso próprio, por que uma alteração especificando melhor os detalhes desta proibição seria a solução? Para que se possa compreender como o operador do Direito enxerga essa abordagem, evoca-se aqui de forma muito sucinta a teoria da interpretação do Direito do jusfilósofo Ronald Dworkin (1999), para quem a interpretação de uma norma busca sempre encontrar a melhor resposta ou solução para determinado questionamento, tornando tal decisão o exemplo a ser seguido pelos demais intérpretes. Nessa linha de raciocínio a interpretação da norma por cada intérprete tende a ser sempre favorável a quem a analisa, ou no caso do julgador, aos seus princípios e entendimento. A interpretação tende a mostrar o que foi interpretado por meio da melhor luz possível, tomando em conta tanto o que já foi decidido anteriormente (que é o caso das jurisprudências), mas, também, como estas decisões foram tomadas. Ou seja, foca-se a atenção não apenas no resultado das decisões, mas em todo o caminho percorrido pelo processo que levou a tal decisão. Fato este relevante para que não seja realizada apenas a simples assimilação de resultados e decisões, sem a menor noção de por que e como se chegou a este resultado. "Os juízes devem tomar suas decisões sobre o "common law" com base em princípios, não em política [...]" (DWORKIN, 1999, p. 292). No pensamento de Dworkin, a interpretação deve corresponder ao ato de descrever os atos como eles são, e não como o intérprete acredita serem. Por isso, a norma deve apresentar a menor margem possível de diversidade de interpretação.

Nesta pesquisa, observa-se que o inciso I do artigo 10 da LPC, referente às sementes salvas, tem causado interpretação divergente daquela estabelecida em sua origem. A confusão generalizada no setor se deve a haver mais de uma interpretação da norma. É preciso ter uma maior clareza na redação do dispositivo, razão pela qual o posicionamento deste trabalho é pela sua alteração.

Considerando-se uma proposta de alteração da lei, baseada nos entendimentos obtidos nesse trabalho, recomenda-se que fosse incluído no texto do inciso I do artigo 10 da LPC, tornando sua redação mais clara, a seguinte expressão: "I - reserva e planta sementes para uso próprio, em seu estabelecimento ou em estabelecimento de terceiros cuja posse detenha, com fins exclusivos de consumo próprio [...]." (BRASIL, 1997, art. 10, grifo do original).

Por mais singela que essa expressão possa parecer, especificar que os fins determinados ao se realizar a prática das sementes salvas sejam exclusivos para consumo próprio, retoma o espírito de elaboração da lei, em que a exceção do direito de propriedade do obtentor não pode interferir na segurança alimentar daquele que reserva e planta sementes. O que foi visto é que o termo uso próprio é o responsável por uma interpretação que vai além do consumo, haja vista "uso" evocar mais de uma acepção para a palavra. A eliminação de dubiedade avoca o direito de uma prática rural para que sua realização esteja em justa e concreta simetria com a norma, segundo o verdadeiro objetivo da lei. 
Desde sua elaboração, em 1997, a LPC tem como objetivo regular as relações de propriedade intelectual de novas variedades de plantas. Suas regulações vão desde a duração da proteção até os requisitos para a sua concessão. Os projetos anteriores que tramitaram no Congresso Nacional fracassaram ao tentar endurecer as sanções ou criar dificuldades por meio de criminalização de condutas, porque isso não traz a mudança de comportamento esperado. Os produtores rurais, destinatários das mudanças pretendidas, devem se sentir colaboradores da transformação do comportamento, tendo por base que nosso ordenamento jurídico tenha critérios objetivos, para evitar violações e dano à propriedade intelectual, evitando suposições ou presunções que desestabilizem a segurança jurídica. Em relação às ponderações já existentes na lei que buscam garantir condições que favoreçam os pequenos agricultores, essas seriam mantidas, até mesmo por uma questão de justiça social, e não se tornaram objeto de proposta de alteração.

\section{Referências}

ABRASEM - ASSOCIAÇÃO BRASILEIRA DE SEMENTES E MUDAS. Anuário 2014. Brasília, DF, 2014. Disponível em: http://www.abrasem.com.br/wp-content/uploads/2013/09/Anu\%C3\%A1rioAbrasem-2014.pdf. Acesso em: 17 nov. 2018.

ABRASEM - ASSOCIAÇÃO BRASILEIRA DE SEMENTES E MUDAS. Anuário 2016. Brasília, DF, 2017. Disponível em: http:/www.abrasem.com.br/wp-content/uploads/2013/09/Anuario_ ABRASEM_2016_SITE.pdf. Acesso em: 17 nov. 2018.

ABRASEM - ASSOCIAÇÃO BRASILEIRA DE SEMENTES E MUDAS. Anuário 2018. Brasília, DF, 2019. Disponível em: http://www.abrasem.com.br/wp-content/uploads/2019/06/Arte_Anuario2018_ COMPLETO_WEB.pdf. Acesso em: 17 jan. 2019.

ABRASS - ASSOCIAÇÃO BRASILEIRA DOS PRODUTORES DE SEMENTES DE SOJA. Combate à pirataria. Brasília, DF, 2016. Disponível em: http://abrass.com.br/semente-de-soja/combate-apirataria/. Acesso em: $05 \mathrm{dez} .2018$.

APASSUL - ASSOCIAÇÃO DOS PRODUTORES E COMERCIANTES DE SEMENTES E MUDAS DO RIO GRANDE DO SUL. RS entre os estados com maior uso de sementes piratas. Notícias APASSUL, 30 out. 2017. Disponível em: http://www.apassul.com.br/noticias/ver_mais/335\#. XTEPXPJKjIU. Acesso em: 12 jan. 2018.

ANTUNES, I. F. et al. Efeitos da Lei de Proteção de Cultivares sobre o desenvolvimento de cultivares de feijão. In: CONGRESSO NACIONAL DE PESQUISA DE FEIJÃO, 9., 2008, Campinas. Ciência e tecnologia na cadeia produtiva do feijão: Anais [...], Campinas: Instituto Agronômico, 2008. (IAC. Documentos, 85)

AVIANI, D. de M. Requisitos para proteção. In: BRASIL. Ministério da Agricultura, Pecuária e Abastecimento. Secretaria de Desenvolvimento Agropecuário e Cooperativismo. Proteção de cultivares no Brasil. Brasília, DF, 2011. p. 37-43. Disponível em: http://www.agricultura.gov.br/ assuntos/insumos-agropecuarios/insumos-agricolas/protecao-de-cultivar/publicacoes/livro-protecaocultivares. Acesso em: 12 nov. 2018. 
AVIANI, D. de M.; MACHADO, R. Z. União Internacional para Proteção de Obtenções Vegetais (UPOV). In: BRASIL. Ministério da Agricultura, Pecuária e Abastecimento. Secretaria de Desenvolvimento Agropecuário e Cooperativismo. Proteção de cultivares no Brasil. Brasília, DF, 2011. 202p. Disponível em: http://www.agricultura.gov.br/assuntos/insumos-agropecuarios/insumosagricolas/protecao-de-cultivar/publicacoes/livro-protecao-cultivares. Acesso em: 12 nov. 2018.

BARBOSA, D. B. A pretensa e a verdadeira crise na proteção de cultivares. Revista Eletrônica do IBPI, Lisboa, n. 7, p. 297-336, jan. 2013. Disponível em: http://ibpieuropa.org/book/revistaeletronica-do-ibpi-nr-7. Acesso em: 3 nov. 2017.

BRASIL. Lei n. 10.711, de 5 de agosto de 2003. Dispõe sobre o Sistema Nacional de Sementes e Mudas e dá outras providências. Diário Oficial [da] República Federativa do Brasil, Poder Executivo, Brasília, DF, 6 ago. 2003. Seção 1, p. 1. Disponível em: http://www.planalto.gov.br/ ccivil_03/LEIS/2003/L10.711.htm. Acesso em: 6 ago. 2018.

BRASIL. Lei n. 11.105, de 24 de março de 2005. Regulamenta os incisos II, IV e V do $\S 1^{\circ}$ do art. 225 da Constituição Federal, estabelece normas de segurança e mecanismos de fiscalização de atividades que envolvam organismos geneticamente modificados - OGM e seus derivados, cria o Conselho Nacional de Biossegurança - CNBS, reestrutura a Comissão Técnica Nacional de Biossegurança - CTNBio, dispõe sobre a Política Nacional de Biossegurança - PNB, revoga a Lei n. 8.974, de 5 de janeiro de 1995, e a Medida Provisória n. 2.191-9, de 23 de agosto de 2001, e os arts. $5^{\circ}, 6^{\circ}, 7^{\circ}, 8^{\circ}, 9^{\circ}, 10$ e 16 da Lei n. 10.814, de 15 de dezembro de 2003, e dá outras providências. Diário Oficial [da] República Federativa do Brasil, Poder Executivo, Brasília, DF, 28 mar. 2005. Seção 1, p. 1. Disponível em: http://www.planalto.gov.br/ccivil_03/_ato20042006/2005/lei/l11105.htm. Acesso em: 6 jul. 2019.

BRASIL. Lei n. 9.279, de 14 de maio de 1996. Regula direitos e obrigações relativos à propriedade industrial. Diário Oficial [da] República Federativa do Brasil, Poder Executivo, Brasília, DF, 15 maio 1996. Seção 1, p. 8.353. Disponível em: http://www.planalto.gov.br/ccivil_03/leis/19279.htm. Acesso em: 6 ago. 2018.

BRASIL. Lei n. 9.456, de 25 de abril de 1997. Institui a Lei de Proteção de Cultivares e dá outras providências. Diário Oficial [da] República Federativa do Brasil, Poder Executivo, Brasília, DF, 8 abr. 1997. Seção 1. p. 251-262. Disponível em: http://www.planalto.gov.br/ccivil_03/LEIS/L9456. htm. Acesso em: 6 ago. 2018.

BRASIL. Ministério da Agricultura, Pecuária e Abastecimento. Fiscalização de Sementes e Mudas. Brasília, DF, 2019a. Disponível em: http://www.agricultura.gov.br/assuntos/insumos-agropecuarios/ insumos-agricolas/protecao-de-cultivar/publicacoes/livro-protecao-cultivares. Acesso em: 16 dez. 2019.

BRASIL. Ministério da Agricultura, Pecuária e Abastecimento. Secretaria de Desenvolvimento Agropecuário e Cooperativismo. Proteção de cultivares no Brasil. Brasília, DF, 2011. 202p. Disponível em: http://www.agricultura.gov.br/assuntos/insumos-agropecuarios/insumos-agricolas/ protecao-de-cultivar/publicacoes/livro-protecao-cultivares. Acesso em: 12 nov. 2018.

BRASIL. Ministério da Ciência, Tecnologia, Inovações e Comunicação. Comissão Técnica Nacional de Biossegurança. Resumo geral de plantas geneticamente modificadas aprovadas para comercialização. [Brasília, DF], 2019b. Disponível em: http://ctnbio.mcti.gov.br/ documents/566529/1684467/Tabela +de+Plantas + Aprovadas + para +Comercializa\%C3\%A7\%C3\% A3o/e3087f9c-c719-476e-a9bd-bfe75def842f. Acesso em: 7 jul. 2019. 
CARVALHO, S. M. P. de; SALLES-FILHO, S. L. M.; PAULINO, S. R. Propriedade intelectual e organização da P\&D vegetal: evidências preliminares da implantação da Lei de Proteção de Cultivares. Revista de Economia e Sociologia Rural, Rio de Janeiro, v. 45, n. 1, p. 9-26, jan.-mar. 2007.

CORDEIRO, A.; PEREZ, J.; GUAZZELLI, M. J. Impactos potenciais da tecnologia Terminator na produção agrícola: depoimentos de agricultores brasileiros. Florianópolis: Centro Ecológico, 2007. Disponível em: http://www.centroecologico.org.br/boletim_download.php?id_boletim=91\&tipo=pdf. Acesso em: 10 nov. 2017.

DINIZ, C. R.; SILVA, I. B. da. Metodologia científica: tipos de métodos e sua aplicação. Campina Grande; Natal: UEPB/UFRN; EDUEP, 2008. Disponível em: http:/www.ead.uepb.edu.br/ava/ arquivos/cursos/geografia/metodologia_cientifica/Met_Cie_A04_M_WEB_310708.pdf. Acesso em: 5 dez. 2018.

DWORKIN, R. O Império do Direito. São Paulo: Martins Fontes, 1999.

EMBRAPA. Mercado de cultivares: perguntas e respostas. Brasília, DF: Embrapa Produtos e Mercados, [2017]. Disponível em: https://www.embrapa.br/tema-mercado-de-cultivares/perguntas-erespostas. Acesso em: 11 out. 2017.

FARIAS, F. Lei das cultivares: agricultores não abrem mão de produzir a própria semente. Canal Rural, Brasília, DF, 14 out. 2015a. Disponível em: https://canalrural.uol.com.br/programas/lei-dascultivares-agricultores-nao-abrem-mao-produzir-propria-semente-59268/. Acesso em: 19 set. 2017.

FARIAS, F. Saiba o que está em jogo com a nova Lei de Cultivares. Canal Rural, Brasília, DF, 15 out. 2015b. Disponível em: https://canalrural.uol.com.br/programas/saiba-que-esta-jogo-com-novalei-cultivares-59286/. Acesso em: 19 set. 2017.

FERREIRA, N. B. V. Possíveis impactos da alteração da lei de cultivares, tendo como base as diretrizes da Convenção de 1991 da UPOV. 2010a. 210f. Dissertação (Mestrado Profissional em Propriedade Intelectual e Inovação) - Coordenação de Pesquisa e Educação em Propriedade Intelectual, Inovação e Desenvolvimento, Instituto Nacional da Propriedade Industrial - INPI, Rio de Janeiro, 2010a.

FERREIRA, S. N. Propriedade intelectual e acesso a recursos genéticos e repartição de benefícios: uma conciliação possível? Brasília, DF: Embrapa Informação Tecnológica, 2010b.

FREITAS, R. de. Projeto de Lei do Senado n. 32, de 2017, que altera a Lei n. 9.456, de 25 de abril de 1997, que institui a Lei de Proteção de Cultivares para estender sua proteção à comercialização do produto final do processo de produção agrícola. Brasília, DF: Senado Federal, 2017. Disponível em: https://legis.senado.leg.br/sdleg-getter/documento?dm $=5047075 \& t s=1559269$ 431099\&disposition=inline. Acesso em: 19 set. 2017.

GALIOTTO, F. Mercado de sementes movimenta $\mathrm{R} \$ 10$ bi ao ano no Brasil. Folha de Londrina, Londrina, 25 fev. 2017. Folha Rural. Disponível em: https://www.abrates.org.br/noticia/mercado-desementes-movimenta-r-10-bi-ao-ano-no-brasil. Acesso em: 07 nov. 2017.

GHESTI, G. F. (coord.). Conhecimentos básicos sobre propriedade intelectual. Brasília, DF: Centro de Apoio ao Desenvolvimento Tecnológico, UnB, 2016. 153p.

GIL, A. C. Como elaborar projetos de pesquisa. 4. ed. São Paulo: Atlas, 2002. 176 p.

LEITÃO, N. Relatório da Comissão Especial destinada a proferir parecer ao Projeto de Lei n. 827, de 2015, que altera a lei de proteção de cultivares. Brasília, DF, 2017. 
LIMA, I. V.; MACHADO, V. L. dos S. Denominação de cultivares. In: BRASIL. Ministério da Agricultura, Pecuária e Abastecimento. Secretaria de Desenvolvimento Agropecuário e Cooperativismo. Proteção de cultivares no Brasil. Brasília, DF, 2011. p. 45. Disponível: http:// www.agricultura.gov.br/assuntos/insumos-agropecuarios/insumos-agricolas/protecao-de-cultivar/ publicacoes/livro-protecao-cultivares. Acesso em: 12 nov. 2018.

MACHADO, R. Z. [RES: APL Cultivares]. Destinatário: Fábio Lima Cordeiro. Brasília, DF, 13 nov. 2017. 1 e-mail.

NUNES, J. L. da S. Tecnologia de sementes - produção. Agrolink, Porto Alegre, 12 set. 2016. Disponível em: https://www.agrolink.com.br/sementes/tecnologia-sementes/producao_361335.html. Acesso em: 7 nov. 2017.

PEIXOTO, J. R.; VILELA, M. S. Visão empresarial de um produtor rural/melhorista sobre o mercado de sementes. In: AMABILE, R. F; VILELA, M. S.; PEIXOTO, J. R. (ed.). Melhoramento de plantas: variabilidade genética, ferramentas e mercado. Brasília, DF: Proimpress; Sociedade Brasileira de Melhoramento de Plantas, 2018. 108p. Disponível em: https://ainfo.cnptia.embrapa.br/digital/ bitstream/item/193840/1/Melhoramento-de-plantas.pdf. Acesso em: 8 jul. 2019.

RODRIGUES, J. A. P.; CAMPANTE, P.; BARRETO, M. A lei de proteção de cultivares e a sua importância para a pesquisa e desenvolvimento de novas variedades vegetais. Anuário Brasileiro de Sementes, Brasília, DF, p. 12-17, 2017.

SANTOS, C. Relatório Legislativo pela aprovação do PLS 32/2017. Brasília, DF: Senado Federal, Comissão de Agricultura e Reforma Agrária, 2017. Disponível em: https://legis.senado.leg. $\mathrm{br} / \mathrm{sdleg}$-getter/documento?dm $=5334779 \& t s=1559269431229 \&$ disposition $=$ inline. Acesso em: 19 set. 2017.

SANTOS, E. V. dos. Teses e dissertações dos Programas de Doutorado Acadêmico e Mestrado Profissional em Propriedade Intelectual e Inovação. Rio de Janeiro: INPI: 2018. 87f. Disponível em: http://www.inpi.gov.br/teses-e-dissertacoes_junho_2018.pdf. Acesso em: 5 ago. 2019.

SILVA, C. M. da. Semente salva: uma análise de benefícios e prejuízos. In: CONGRESSO BRASILEIRO DE ALGODÃO, 5., 2005, Salvador. Algodão, uma fibra natural: resumos... Salvador, BA: Embrapa Algodão, 2005. Anais [...], Salvador, BA, 2005, 220p. Disponível em: http://www. cnpa.embrapa.br/produtos/algodao/publicacoes/trabalhos_cba5/index.html. Acesso em: 5 dez. 2018.

SILVEIRA, D. T.; CÓRDOVA, F. P. A pesquisa científica. In: GERHARDT, T.; SILVEIRA, D. T. (org.). Métodos de pesquisa. Porto Alegre: Ufrgs, 2009. Cap. 2. p. 34-42.

SNPC. Sistema Cultivar Web. Brasília, DF: Ministério da Agricultura, Pecuária e Abastecimento, 2019. Disponível em: http://sistemasweb.agricultura.gov.br/pages/SNPC_CW.html. Acesso em: 5 jul. 2019.

UTINO, S. Lei de proteção de cultivares. In: SILVEIRA, P. M. da (ed.). Feijão. Goiânia: Embrapa Arroz e Feijão, 2012. Disponível em: https://www.agencia.cnptia.embrapa.br/gestor/feijao/arvore/ CONTAG01_118_131120039558.html. Acesso em: 19 set. 2017. 


\section{Sobre os Autores}

\section{Fabio Lima Cordeiro}

E-mail: agaciel@hotmail.com

Mestrado.

Endereço profissional: Universidade de Brasília, Campus Universitário Darcy Ribeiro, Asa Norte, Brasília, DF. CEP: 71910-900.

\section{Luiz Antonio Soares Romeiro}

E-mail: luizromeiro@unb.br

Doutorado.

Endereço profissional: Universidade de Brasília, Campus Universitário Darcy Ribeiro, Asa Norte, Brasília, DF. CEP: 71910-900. 